\title{
ISSUES AND CONCERNS IN THE IMPLEMENTATION AND MAINTENANCE OF HRIS
}

\author{
Sandeep K. Krishnan \\ Manjari Singh
}

W.P. No. 2006-07-01

July 2006

The main objective of the working paper series of the IIMA is to help faculty members, Research Staff and Doctoral Students to speedily share their research findings with professional colleagues, and to test out their research findings at the pre-publication stage

\section{INDIAN INSTITUTE OF MANAGEMENT \\ AHMEDABAD-380 015 \\ INDIA}




\title{
ISSUES AND CONCERNS IN THE IMPLEMENTATION AND MAINTENANCE OF HRIS
}

\author{
Sandeep K. Krishnan \\ Doctoral Student \\ Personnel and Industrial Relations Area \\ D-18, Indian Institute of Management, \\ Vastrapur, Ahmedabad 380 015, \\ Gujarat, India. \\ Email: sandeepk@iimahd.ernet.in \\ Tel: ++91-79-26327816 \\ Fax: ++91-79-26306896
}

\author{
Manjari Singh \\ Faculty \\ Personnel and Industrial Relations Area \\ Wing 12-D, Indian Institute of Management, \\ Vastrapur, Ahmedabad 380 015, \\ Gujarat, India. \\ Email: manjari@iimahd.ernet.in \\ Tel: ++91-79-26325316 \\ Fax: ++91-79-26306896
}

\begin{abstract}
The paper looks at the issues and concerns faced by nine Indian organisations in implementing and managing HRIS. The organisations are diverse in terms of size and sector that they belong. The critical success factors and weaknesses in various stages of implementing an HRIS are explored in the paper. The problems are rooted in mainly two factors. One is the fact that HR department lacks knowledge about HRIS and hence is not able to clearly elucidate the requirements of the system. Poor need assessment is a continuation of this problem. Second is the lack of importance given to HR department in the organisations.
\end{abstract}

The spectrum of cases covered shows the clear variation in terms of the success of implementation. In poorly managed implementations, the potential of HRIS has been under-utilised. Only a few modules have been implemented and at best HRIS's role is that of a centralised database. Very high dependence is placed on the vendors without having a clear idea about how to select vendors or a proper process or contract to ensure vendors' accountability. Another area of concern is that level of cooperation needed across various functions and divisions of the organisation for proper implementation of HRIS is also lacking. User satisfaction is low because there is minimal user involvement in the implementation project and the implemented package is not user-friendly.

Key Words: HRIS, implementation 


\section{ISSUES AND CONCERNS IN THE IMPLEMENTATION}

AND MAINTENANCE OF HRIS

\section{Introduction}

Human resource information system (HRIS) uses the information technology developments and features for effective functioning of the HR processes. The major objectives may be giving better service, information access, cost saving, or efficiency in terms of speed of execution. Some of the stated advantages of automating human resource functions are: increased data accuracy, increasing processing speed, creating more useful and sophisticated results, and increase in productivity (Ceriello and Freeman, 1998). The outcomes that are generally stated in terms of management processes are: enhancement in executive decision making, employee training, technology usage, interdepartmental integration, and better reporting structures (Mayfield, Mayfield and Lunce, 2003). In an ideal situation HRIS should aid in strategic integration, personnel development, communication and integration, records and compliance, human resources analysis, knowledge management, forecasting and planning, and moving forward towards the organisational vision (Mayfield et al., 2003). However in most of the cases, the strategic relevance is not understood or achieved (Tansley and Watson, 2000).

The broader dimensions of HRIS are the technological factors like the infrastructure for HRIS and the softer dimensions includes the integration of the HR processes and functions, which are mostly organisation dependent. Implementation of HRIS thus involves managing the technical dimensions and the organisational factors. The technical factors include selecting and managing the vendors on the basis of various factors like cost and features. The organisational process handling may involve adaptation to the software, policy changes and host of other factors. Implementation of HRIS and its maintenance requires lot of organisational resources and project management skills. Implementation of HRIS is seen through a project management approach taking care of each stage. In the similar lines Schultz (1997: 37) has stated that "every implementation is actually composed of at least four separate "projects": Identifying the problem and analyzing business needs that must be met, evaluating vendors and selecting a system, implementing a solution, and conducting a post-implementation audit." Further, Singh 
(2002) states that the proper management of each of stages is critical for the success of any HRIS implementation.

The paper looks into the issues and concerns in the three main stages in the implementation of HRIS. These three stages are: pre-implementation, implementation, and post-implementation. Hence, the paper explores the following objectives from the perspective of the respondents' experiences of selecting and implementing HRIS:

a) Major factors that will lead to success of HRIS implementation,

b) Major impediments to HRIS implementation in various stages, and

c) Recommendations for a successful implementation of HRIS.

\section{Issues and concerns in the implementation of HRIS:}

\section{Pre-implementation stage:}

The pre-implementation needs will be looking into the business objective of having a HRIS, the prioritisation of inclusion of the various HR functions, a need analysis based on the various factors including the technical and personnel related, negotiations within the organisational and external constituents like the vendors and other departments, and having a pre-assessment.

The major challenges here would be convincing the top management, getting the best deal from the vendors, and matching the organisational processes (HR processes) with the software. Creating value for the organisation through increased functionalities would be of importance. Some of the outcomes that management is looking in HRIS are: performance management, workforce alignment, and employees' support of corporate goals (HR Focus, 2003).

The strategic considerations also come into play while envisaging the implementation of HRIS. With the increasing trends in home working, networked jobs, and globalization and associated increase in expatriates, HRIS is often used to cater to such needs. The adaptation issues of HRIS to the local needs and connectivity features are important considerations. The need analysis focuses on the features that the HRIS system software 
requires. For example, in the global HRIS information system, the integration issues, the hardware and software requirements, and the cross-cultural and national differences should be taken into consideration (Hannon, Jelf and Brandes, 1996).

Selection of the system depends on the user needs. The functions of HRIS to be automated will be an important factor in selecting HRIS. Also some of the selection will be based on the replacement needs or upgradation. So the specific features required will have importance. The replacement or upgradation will be based on the feedback on performance after the implementation or due to emergence of new needs. Studies have shown that certain functions of HR are given priority over other during adopting HRIS. Functions like personnel administration and pay roll are the most commonly automated HR functions (IOMA's Report, 2001a).

Usually teams from different department including HR and purchase are formed to get a consensus on the cost aspect, the strategic aspects, and the features to be included in the HRIS. The needs formulated helps in short-listing and selecting the vendors. Wisner and Wisner (1994: 19) states that for understanding the organisational needs and translating them to select the best product possible, "a system evaluation/selection team of four or five members should be formed, including at least one member from the HR, information systems and purchasing departments". Team members need to identify and agree on evaluation factors with corresponding numbers for relative importance and minimum acceptable performance level. Evaluation factors should concentrate on system capabilities, operating characteristics, and cost.

To understand the possible ways of looking into the implementation of HRIS, organisations can also look into how similar organisations have done the management. The basic assessment of requirements like features required, safety concerns, and customization required is followed by evaluation of the vendors and systems offered. An option that arises here is to outsource the HRIS. However the concerns of safety in maintaining the details in a third party server, concerns over commitment and accountability of the vendor, dealing with organisational specific needs, etc. arises. The concern of data security after a possible switching to another vendor also arises (HR Focus, 2002 and HR Focus, 2001, IOMA's Report, 2001b). Selecting the vendor requires extensive negotiations and assessment before decision-making. Hidden costs, which are 
associated with the implementation, should be explored before making the decision. The apparent costs for HRIS may be the computer costs, overhead, software and personnel but the major hidden costs like documentation costs, operations overload, inadequate priority analysis of competing applications, poor division of labour, security and privacy issues, improper use of management time, training and recruitment, etc. should be looked into (HR Focus, 2001). Some of the hidden costs like technical support, user training and maintenance can be entrusted to the vendor if effective negotiations are made (IOMA's Report, 2002b). The major factors that are considered are based on costs, efficiency, maintenance contracts, time for implementation, user friendliness, and customization required to fit with organisational requirements (Singh, 2002).

Before the implementation of HRIS the major factor would be the adaptation of the HR processes. Although some customised softwares can look into the specific needs, one of the major motives of the HRIS would be to improve the existing systems. A workflow analysis is usually done and processes are analyzed for possible improvements (Walker, 1993). Study by Singh (2002) finds that the customization of the HRIS is one of the least important concerns as most organisations decide a priori not to customise but to adapt to the features of the system.

\section{Implementation stage:}

This is the phase after the selection of the HRIS. The phase is characterised by setting up the infrastructure for HRIS, coordination between the HR and other departments for integrating the system with the organisation, formulation of policies and rights for users, personnel training, and testing and optimizing the performance.

The project management aspects like getting the resources ready, getting the right people, communication issues, other factors such as the legal requirements, etc. should be taken care during this period. There are issues due to conflicts among the project members of HRIS, which may arise because people are set in their ways, or want to perpetuate traditional corporate processes or procedures (Jossi, 2001). To help avoid this type of conflict, team members should be encouraged to challenge old ways of thinking. A clear project plan and understanding of user needs are the means to solve such issues. 
User training is a key factor in the HRIS implementation. It is often found that HRIS features are not used completely due to the lack of knowledge of the HR managers about the full features, the lack of computer awareness of the personnel or the difficulty in using the systems. Understanding the users and their needs should be augmented with proper training and installation of user-friendly systems. Providing training just before live use begins helps minimise the time between training and actual use of the system. Also the implementing staff needs training on the use of the product. During the early days of implementation, the staff can ask questions about the software, practice on it before it goes live, and deal with unexpected issues that arise during implementation so that they will be better equipped to meet the needs of users (Jossi, 2001). Mostly vendors do the training in the initial phase, followed by developing in-house expertise and then moving for third party after analyzing the cost consideration and the service periods. However computer illiteracy and lack of understanding of basic platform like Windows can double the training job to be done (Elliot, 1999).

Next major issue in the implementation phase is the formulation of policies and procedures for HRIS. The online database and information causes concerns in terms misuse of data and data security. Organisational policies are to be framed for the use of the online data. This may also comply with the national and international standards of information system usage. The HR policies should be explicit in terms of monitoring of data by employers, the terms and condition of usage of the internet and HRIS features and data sharing (IOMA's Report, 2001d). The privacy concerns of employee should also be addressed, proper training on how to use the HRIS, password protection procedures and standards, setting the access rights, and remaining focused on the purpose for and amount of data collected (Hubbard and Forcht, 1998). Data entry and the need of specific data to be entered into the system should be validated during the implementation stage. This is an important factor as any slack in this process may lead to redundant data and data errors in the system.

\section{Post-implementation stage:}

The post implementation stage is characterised by focus on the performance of the HRIS, maintenance, and upgradation or replacement according to the new needs and technological advancements. The maintenance in the broader sense may include the 
corrective maintenance either due to errors in the software or installation, adaptive maintenance according the changes in the legal setup or organisational needs or perfective maintenance like refining of data or updating virus definitions (Ceriello and Freeman, 1998).

Significant operational issues like lack of personnel, time, system failures, lack of resources, and coordination problems with other departments also characterise the post implementation phase. Studies have shown that lack of money, staff, and time are the toughest problems faced (IOMA's Report, 2002c). The performance measurement of HRIS is another factor during the post implementation stage. Management would be concerned about the ROI from the HRIS and the increase in efficiency made possible by the system. The savings and effectiveness is expected in terms of better communication, easy availability of information, savings in terms of paper work, and various administrative routines.

Continuous organisational change is also expected after the implementation of HRIS. The responsibilities and competencies of HR managers will be redefined according the HRIS requirements. This may include technical competencies, cost consciousness and consulting capabilities (Hagood and Friedman, 2002). A restructuring of the organisation is also expected, as some of the administrative issues in HR management will be handled by the system.

As a whole HR department has a critical role to play in the process through out the implementation. From properly defining needs based on the job tasks to be automated to final change management, HR can play a critical role in terms of need assessment, interventions in terms of training and rewards, and providing relevant information for decision support (Bondarock and Looise, 2005).

\section{Methodology}

The paper presents insights into the process of HRIS implementation through nine cases. The organisations are in different stages of implementation and are faced with some unique difficulties. C-two Limited is planning to implement an HRIS and has finalised on the package of be implemented and has decided on the consultants to be 
employed. C-three Limited, C-five Bank, C-seven Limited and C-one Appliances have implemented a customised package. C-six Technologies and C-four Limited have implemented standard HRIS packages. C-eight Technologies and C-nine Limited are cases of more successful implementations. C-eight Technologies has developed the entire HRIS implementation in-house. C-nine Limited has implemented a standard HRIS package and has built up an internal specialists' team that can handle the day-to-day administration and maintenance of the system.

The details about the implementation process were obtained from the HR managers of the respective companies through direct one-to-one interviews. The managers who were interviewed were either involved in the process of implementation or they had good understanding of the process of implementation. Many of the respondents could relate themselves to the issues involved in the HRIS implementation process. A questionnaire was used to structure the interview and to get relevant information. The data was collected during the year 2003-04.

\section{C-one Appliances}

C-one Appliances is a FMCG company focusing its operations in the household insecticide segment. The company has around 400 employees. The HR department is small and has only 2 HR executives. All functions of the company, except HR, have implemented an ERP package.

Although HR department was given less importance in the company, growth of the company posed a challenge of managing the HR in a better manner. As the HR executive puts it "As usual HR gets it last". HR department was not involved in the early phases of the HRIS implementation especially in the need assessment phase. It got involved from the testing phase. The company developed HRIS software in-house with the expertise of a small-scale software services organisation. The software was developed using Java and Oracle platform. The project was executed within a period of 6 months and it has been operational for 8 months at the time of the interviews conducted for this study. The software handled the payroll of the company. The software has a depository of the profile of the entire employees of the company. The company has plans to include more modules for other HR sub-functions. 
As per the company source, the vendor customised an already available product for the company. The organisation had several problems in terms of need assessment. Both the organisation and vendors did not have clear idea about the needs and also about the process to meet these needs. Although the basic programme works well, once advanced features of the programme were used more bugs came up. There are issues with the reports that can be generated and some of the necessary reports are missing. Statutory compliances are still missing in the software. The software is also rated poor in terms of user friendliness.

As of now only the HR department has access to the system. The system acts as a centralised database. Even in the later stage, providing access to all the employees would be a challenge due to investments required in terms of hardware to provide connectivity and the lack of computer literacy of the employees.

As far as the cost for the system is concerned, while looking at the ROI as per the current level of service provided by the software, the cost cannot be justified. The support provided by the vendor is considered good, however the cost for the support is also high. Also there is a worry that only one person of the vendor firm has reasonable knowledge about the system and therefore chances of providing sustained product support is at risk. The recurring cost for upgradation and maintenance is high. The company feels that poor negotiation and contract formulation has resulted in high recurring and maintenance costs. On the whole, the company feels that the software is a mere database.

\section{C-two Limited}

C-two Limited is a member of a major multinational group and has around 1300 employees. The company is in the process of implementing a well-known package for its HRIS. Implementation of HRIS and selection of the package are mainly due to the pressure from the parent company. The reason for choosing the specific software package is two-fold. One, the company already uses that package for other functions and hence the integration of HRIS with the organisation would be easier. The particular HRIS package also has the capability to provide worldwide connectivity. The company has already signed up two major consultants (Business and IT) who will be helping in the entire 
implementation process. The company believes that implementation of HRIS would add value in terms of improved efficiency and decision support.

Understanding the system and training the employees are the anticipated challenges in the implementation. However the implementation process is getting good support from the senior management as it an initiative of the parent company. The parent company is aware of the benefits of implementing HRIS and is encouraging implementing it in other group companies.

The company plans to use HRIS for a broad range of HR sub-functions. The HR department wants the system to be user friendly and customised to the needs of the company. The HR department feels that one and a half years would be a reasonable time period for the implementation of the system and its acceptance by the employees.

\section{C-three Limited}

$\mathrm{C}$-three is a major player in the health drink market. The company has around 3500 employees. The HR department initiated the HRIS project of the company. The project implementation process took around 8 months and was formally completed by January 2002. The company choose to employ an IT major to develop a customised product. The IT services company could offer a cheaper product that took care of the special requirements of the company. However in the planning and implementation, the company had serious troubles in finalising the requirements. Also the lack of experience of the vendor in handling similar projects and confusion of the client about what they require led to a lot of issues.

The IT and HR teams of the organisation were involved in the HRIS project. Primarily HR department was involved in handling the need assessment and mapping the process flows. After the installation of software, two rounds of exhaustive training were provided to the HR managers who in turn rolled out the training knowledge to the employees in their units.

The HRIS covers around one-third of the employees in the organisation. All employees, except the field staffs and the lower rung employees, were covered. The 
system acts as a centralised database and provides communication media for the employees. Most of the major HR activities are handled by the HRIS. Performance Appraisal is one of the areas where the software is widely used.

The performance of the HRIS is far from optimal. The software has lots of bugs and with usage more bugs are discovered. This has led to a lot of parallel processes to ensure that there will not be any hindrances in the work. The parallel processes have led to duplication of processes and also a lot of paper work. The clauses in the contract, which defines the relationship with the vendor and the clearance for the software after testing, are considered critical as these can determine the cost to the company and the quality of vendor service.

The company has established policies for privacy maintenance. However more of privacy issues arise due to ignorance on the part of employees. Password sharing and lack of seriousness in using the system properly are some of the reasons for privacy issues.

Although the present system may take more time to stabilise, at present it functions efficiently as a central depository of employee details and has improved efficiency to some extend due to real time updation and easy process for approvals.

\section{C-four Limited}

C-four Limited is an engineering company that has 1500 employees, out of which around 800 are qualified and trained engineers and scientists. The company has a turnover of around 6000 millions. The company had a legacy system bought from an external agency. A well-known company developed the HRIS that is been currently been used. The system was selected after considering the needs and the suitability of the package for the organisation. Interestingly the present HRIS package came free with a software package that is being used by the organisation.

All the employees are covered by the existing system. The system is used as an employee data depository and for payroll, compensation management, and Industrial Relations related activities. The present system does not handle performance appraisal or 
other functions like career planning or training and development. A different system using Lotus Notes is developed for handling performance appraisal and career planning.

The organisation does not find the performance of HRIS completely satisfactory. Apart from the problems due to lack of user friendliness, poor support from the vendor in terms of maintenance and upgradation has caused trouble. Both the vendor and the organisation lack in-depth knowledge of the system. The company employees who were involved in its implementation and the employees of the vendor who were involved in the development and implementation have left their respective organisations. This has led to poor support for maintenance of the HRIS. The company had to develop their own excel sheets to meet the demands of newly arising needs.

The company is planning to get the system online and to give employees direct access to their information. The employees have good working knowledge of computers. However this involves cost in terms of hardware installation and training to employees.

The organisation feels that they are not using the features of the software to full potential. However the system serves the purpose of a good database and helps in increasing the efficiency of the HR department. At present updating the data is an issue for the company.

\section{C-five Bank}

C-five bank has around 5000 employees and is a fast growing bank. The company has around 260 branches and has a presence in almost all the states in the country.

The HRIS was developed by a multinational IT major. HR department initiated the HRIS project and played a major role in its implementation process. IT department also played a major role with the HR department in the project implementation. However the project took more time than expected. The lack of proper assessment of needs and ever changing and increasing needs extended the project period. The increased expectations from the management also increased the pressure on the project team. 
The implemented HRIS acted as a database that contained the employee profiles, including details about employee qualifications and transfers. However some of the basic HR sub-functions like performance appraisal were still manually done. The present system is a central database of the employee details. There is no proposal at present to upgrade the present system.

Access to the system at present is limited to select HR executives. The training of users is in progress and it will take some time to get used to the system.

As far as benefits of an HRIS are concerned, the system has helped in speeding up the HR operations. The response time of the HR department has improved. However since the system has been operational for only six months at the time of this study, it was too early to comment on the benefits of the system.

\section{C-six Technologies}

C-six Technologies operate with around 350 employees in India. The company has implemented the HRIS of a well-known HRIS provider. The system has been operational since one year. As C-six worldwide is using that product, the Indian operations had very less options but to implement the same.

The need and use of HRIS software was not understood well by the HR department in India. Microsoft Excel was used to handle the employee details and calculations in the company prior to the implementation of the software. The package handles most of the HR sub-functions in the company. However some of the areas of work are still done using Excel. The HRIS package is customised for the needs of an American organisation and lacks flexibility to operate in the Indian environment.

The use of the software is made mandatory for the employees. The routine activities like leave processing, etc. are done by the software and use of paper-based application forms are eliminated. The company provided special training to all its HR executives and computer-based training was provided to all the employees reducing cost and time involved in classroom based training. The computer savvy work force helped in the 
implementation of the software and also to make it easier to use it for internal communication.

The support provided by the vendor is considered satisfactory by C-six. The lead-time for handling complaints and the downtime of the software is very less. The package helps in decision support and helps HR department in providing strategically important suggestions. The speed of operation of the software is fast and provides good predefined reports.

\section{C-seven Limited}

$\mathrm{C}$-seven Limited is a major player in the consumer appliances market. The company has around 2500 employees. The HR department initiated the HRIS project in the company. A customised software developed by a major IT service provider in the country was used to support the HRIS. The system has been operational for two months.

The software acts as a centralised database of all white-collar employees. The system handles basic operations related to payroll administration and performance management. The intranet site associated with the HRIS is an effective tool for internal communication.

Training was provided to the HR executives for the use of the software. Employees were given training through intranet, notice boards, and meetings arranged for facilitating the understanding about the software. As part of the implementation, the managing director of the company addressed all the employees and conveyed the message about the importance of the system.

The company at present is satisfied with the progress that the HRIS project is making. The relationship with the vendor is also considered satisfactory.

\section{C-eight Technologies}

C-eight Technologies is a major player in the software services field in the country. It is a growing organisation with more than 20000 employees working in different parts of the globe. The information system and internal communication system in the organisation 
was very difficult to manage because it is not easy to even have an accurate figure about how many employees are working for the company. The top management initiated the HRIS to have reliable database and internal communication system for the company.

The HRIS was developed in-house to incorporate considerable customisation at reduced cost. HR department was involved from the initial stage of the process. A team was constituted with representatives from various departments to manage the process of implementation of the HRIS package. The project was completed within a period of 9 months and the implementation was well within the schedule. It took almost 5 to 6 months to stabilise the HRIS.

The HRIS is internet-enabled and can be access by employees across the globe. The software provides automated solutions for leave processing and for project personnel allocation. At C-eight, all the major HR sub-functions are done with the HRIS support. Performance management is enabled with a special tool. The HRIS is used in internal communication. It also works as a platform for employee training.

The management of change to adapt to the new system involved a lot of problems due to difficulty in adjusting to the new system, problem in updating data, data duplication, and data errors. However the system is equipped with clear deadlines and messaging facilities to help the concerned employee remember about updating the changes and adding information. The new system reduced the paper work to be done for each of the processes. As there was a 150 member strong team for looking after each of the minute details regarding HRIS, slightest of the problems during the usage of the HRIS were well attended to.

\section{C-nine Limited}

Implementation of HRIS in C-nine Limited is an excellent example of how planning and devoted efforts can pull up optimum results out of an HRIS solution. The HR department initiated the HRIS in the organisation. The major reasons for it were: lack of a good database, errors and problems regarding record management, duplications in transactions, and high level of administrative workload on the HR department. 
The company implemented an HRIS solution from a well-known vendor. An internal team was also formed to look after the implementation and maintenance work on the system for reducing the cost and lead-time. The company spent around 6 months on the need analysis process of HRIS. One year was dedicated towards the development and implementation of the software and an additional 6 months were used for the change management process. During the change management period, the legacy systems also run along with the new HRIS. This helped in a smooth transition and in detecting various bugs in the implementation process. During the change management period, extensive feedback was collected from the users to understand the various defects in the software. Exhaustive training was provided to all the employees. To the lower level employees, computer training allowance was provided to help them use the system. A special bonus incentive was also provided for the lower rung employees. The usage of the new HRIS was institutionalised throughout the organisation through a collective labour agreement.

The implementation of the system was delayed due to confusion on both the vendor's and the client's side. High turnover of employees who were involved with the project implementation on the vendor's side was a major reason for the delay. The high cost of the software also caused delay in getting concurrence on the choice of vendor. However as the organisation has built its own team for maintenance, the costs after implementation are minimal.

The implementation of the HRIS has resulted in optimum use of the manpower resources and has minimised administrative work. The outcome was reduction of manpower in the HR department to almost one third. The HR department was also reorganised to handle more strategic roles.

\section{Conclusion}

The cases give the critical dimensions of success and reasons for poor implementation of HRIS in organisations. From the case description we can see that C-nine and C-eight have implemented the system quite effectively. The broader dimensions of factors for each of the three stages (pre-implementation, implementation and post-implementation stages) are discussed in Table 1. 
Table 1: Key observations from the cases to indicate the success factors and the deficiencies

\begin{tabular}{|c|c|}
\hline \multicolumn{2}{|r|}{ Pre-Implementation Stage } \\
\hline \multirow{3}{*}{$\begin{array}{l}\text { Business reason for } \\
\text { HRIS }\end{array}$} & Mostly suggested from the top management. \\
\hline & $\begin{array}{l}\text { Improved work processes and administration expected; better information } \\
\text { availability also indicated. }\end{array}$ \\
\hline & $\begin{array}{l}\text { Lack of clarity about why it is done is seen as a critical reason for delays and } \\
\text { poor implementation. }\end{array}$ \\
\hline \multirow[b]{2}{*}{ HR involvement } & HR department sidelined in a majority of cases. \\
\hline & $\begin{array}{l}\text { Involvement of the HR department is high when the HRIS need is suggested } \\
\text { and pushed by it. }\end{array}$ \\
\hline \multirow{3}{*}{$\begin{array}{l}\text { Overall planning in } \\
\text { the pre- } \\
\text { implementation } \\
\text { stage }\end{array}$} & $\begin{array}{l}\text { Defining the requirements properly is seen as a critical factor for successful } \\
\text { implementation. }\end{array}$ \\
\hline & In most of the cases, requirements do not drive the planning. \\
\hline & $\begin{array}{l}\text { Lack of planning and coordination between the different departments is seen as } \\
\text { a slack area. }\end{array}$ \\
\hline \multirow{3}{*}{$\begin{array}{l}\text { Vendor choice/ } \\
\text { characteristics }\end{array}$} & Cost drives the choice of package in most of the cases. \\
\hline & If cost not the major criterion, then the trend is to choose established vendors. \\
\hline & Need for customisation is often linked with cost concerns. \\
\hline \multicolumn{2}{|r|}{ Implementation Stage } \\
\hline \multirow{2}{*}{$\begin{array}{l}\text { Implementation } \\
\text { team characteristics }\end{array}$} & $\begin{array}{l}\text { One of the obvious success factors is having a well-established multi-functional } \\
\text { team to look after the implementation right from the planning stage. }\end{array}$ \\
\hline & $\begin{array}{l}\text { In most of the cases, lack of effective implementation seem to go with the fact } \\
\text { that HR department is either given less importance or does not effectively } \\
\text { participate. }\end{array}$ \\
\hline \multirow{2}{*}{$\begin{array}{l}\text { Implementation } \\
\text { period and major } \\
\text { implementation } \\
\text { tasks }\end{array}$} & The stated period is generally between six months to two years. \\
\hline & $\begin{array}{l}\text { Major implementation tasks include selection of the vendor, realisation of the } \\
\text { requirements, user training, infrastructure set up, and change management. }\end{array}$ \\
\hline \multirow{2}{*}{$\begin{array}{l}\text { Major modules } \\
\text { implemented and } \\
\text { their coverage }\end{array}$} & $\begin{array}{l}\text { Major modules are payroll, performance management, communication, training } \\
\text { needs, workforce database, and other major HR sub-functions. }\end{array}$ \\
\hline & $\begin{array}{l}\text { In many cases where there is no clear vision regarding the use of HRIS, it has } \\
\text { become merely an information database. }\end{array}$ \\
\hline \multirow{3}{*}{$\begin{array}{l}\text { Major issues in } \\
\text { implementation }\end{array}$} & Attrition of key personnel in the organisation as well as on the vendor's side. \\
\hline & Development of the software delayed due to unclear requirements. \\
\hline & Lack of competence of the vendor. \\
\hline
\end{tabular}




\section{Post-Implementation Stage}

\begin{tabular}{|c|c|}
\hline \multirow{2}{*}{$\begin{array}{l}\text { Implementation } \\
\text { satisfaction }\end{array}$} & $\begin{array}{l}\text { Satisfaction is generally seen to be high with standard established packages } \\
\text { having only minor customisation based on organisational needs. }\end{array}$ \\
\hline & Low level of satisfaction in most of the cases and lack of optimal usage. \\
\hline \multirow{4}{*}{$\begin{array}{l}\text { Major issues post } \\
\text { implementation }\end{array}$} & Bugs in the software. \\
\hline & User-acceptance issues. \\
\hline & Running of dual parallel processes (automation along with manual paperwork). \\
\hline & High maintenance costs. \\
\hline \multirow{6}{*}{$\begin{array}{l}\text { Reasons for } \\
\text { problems }\end{array}$} & Lack of proper needs assessment. \\
\hline & Lack of support from the vendor. \\
\hline & Attrition of key personnel in the organisation and/or on the vendor's side. \\
\hline & High recurring costs due to poorly negotiated contracts with the vendor. \\
\hline & Ignorance of employees regarding the use of the system. \\
\hline & Poor change management. \\
\hline \multirow{2}{*}{$\begin{array}{l}\text { Future plans post } \\
\text { implementation }\end{array}$} & Better utilisation by using more options of the package. \\
\hline & Upgrading the system. \\
\hline
\end{tabular}

The case studies show that successful implementation of HRIS requires thorough planning and monitoring. It is interesting to observe that in most of the cases HR department had no opportunity to select the package they would like to implement according to their needs. Most of the companies prefer customised packages but the confusion about the process to be automated and its translation in the HRIS leads to increased cost and trouble in implementing the system.

There was increased cost and delay in implementation because needs assessment was not done properly. As also seen from the literature, lack of awareness and adaptability to the software caused improper or sub-optimal utilisation of the system. Lack of proper vendor support post implementation can create problems in the operation and maintenance of the system. It is important to understand that the implementation and maintenance is a process requiring continuous support from the organisation and the vendor.

HRIS implementation is a strategic decision for organisations. A well-crafted implementation process involves devotion of time and effort towards needs assessment 
and vendor selection. Multi-functional effort is essential for meeting the purpose of HRIS.

The role of HR department, vendor selection and management of change are critical for the success of HRIS. Interestingly we also observed from the cases that forward-looking and new age industries are more successful in the implementation. A possible explanation would be the profile of the work force that is more techno-savvy. Also, there has been a conscious effort by the organisation to build the internal capability to manage the technical part of HRIS (including maintenance and upgradation) and thus reducing the dependency on the vendor. Cases also point towards the lack of implementation/use of much relevant functionality in the package. Either the users including the HR department are unaware of the functionalities or the change management processes might be too difficult to manage. As most of the known vendors in the HRIS space has highly westernised systems to offer and organisations in the Indian context find its interface quite alien.

As seen in the case of C-nine Limited, successful implementation requires that outcome of HRIS implementation involves internal capacity building, streamlining of processes and commitment for the change management. A critical outcome of HRIS should be that HR department devolves administrative tasks and automates them. Finally, the learning from the nine cases strongly support Mayfield et al. (2003) that HRIS implementation should be carefully planned to achieve best possible outcomes.

\section{References}

BONDAROUK, T., \& LOOISE, J.K. (2005). HR contribution to IT innovation implementation: Results of three case studies. Creativity and Innovation Management, 14(2): 160-168.

CERIELlO, V.R, \& FREEMAN, C. (1998). Human Resource Management Systems: Strategies, Tactics and Techniques. San Francisco: Jossey-Bass.

ELLIOT, R.H. (1999). Computer literacy and human resource management: A public/private sector comparison. Public Personnel Management, 28 (2): 259-275.

HAGOOD, W.O., \& FRIEDMAN, L. (2002). Using the balanced scorecard to measure the performance of your HR information system. Public Personnel Management, 31(4): 543-558.

HANNON, J., JELF, G., \& BRANDES, D. (1996). Human resource information systems: Operational issues and strategic considerations in a global environment. International Journal of Human Resource Management. 7 (1): 17-32.

HR Focus .2003. What are the top HRIS issues in 2003, 80 (5): 2-5.

HR Focus. 2001. What are your peers doing to do HRIS performance? 78 (1): 5-7.

HR Focus. 2002. Question to ask before you outsource any HRIS, 79 (2): 5-6. 
HUBBARD, J.C., and FORCHT, K.A. (1998).Human resource information systems: An overview of current ethical and legal issues. Journal of Business Ethics. 17 (12): 1319-1323.

IOMA's Human Resource Department Management Report. 2001a. What HR functions are most often shifted to HRIS, March: 10-12.

IOMA's Human Resource Department Management Report. 2002c. Lack of money,staff and time toughest part of managing HRIS, December: 3-5.

IOMA's Report on Managing HR Information Systems. 2001c. Sample HR policy language governs use of internet and HRIS, May: 10-12.

IOMA's Report on Managing HR Information Systems. 2001d. A 13-Point plan to protect your HRIS from cyber attacks, November: 3-5.

IOMA's Report on Managing HR Information Systems. 2001b. How Chevron leveraged its HRIS to manage an expatriate work force, April: 2-3.

IOMA's Report on Managing HR Information Systems. 2002a. 20 questions that will uncover hidden HRIS vendor cost, February: 2-3.

IOMA's Report on Managing HR Information Systems. 2002b. How to resolve conflicts with HRIS project team members, March: 6-7.

JOSSI, F. 2001. Get the most out of HRIS training. HR Magazine, 46 (3): 121-126.

MAYFIELD, M., MAYFIELD, J., \& LUNCE, S. (2003). Human resource information systems: A review and model development. Advances in Competitiveness Research, 11 (1): 139-152.

SCHULTZ, J. 1997. Avoid the DDTs of HRIS implementation. HR Magazine, 42 (5): $37-$ 42.

SINGH, M. (2002). Issues related to selection and implementation of IHRIS: A study of 10 organizations. IHRIM Journal, 6 (5): 45-54.

TANSLEY, T., \& WATSON, T. (2000). Strategic exchange in the development of human resource information systems (HRIS). New Technology, Work and Employment, 15 (2): 108-123.

WALKER, A.J. (1993). Handbook of Human Resource Information Systems: Reshaping the Human Resource Function with Technology. New York: McGraw Hill.

WISNER, C.J, \& WISNER, J.D. (1994). Selecting and installing applicant tracking systems. HR Focus, 71 (2): 19. 